$0 / 18928 \delta(2)$

PPPL-2842

UC-420
PREPARED FOR THE U.S. DEPARTMENT OF ENERGY, UNDER CONTRACT DE-AC02-76-CHO-3073

PPPL-2842

SCRAPE-OFF LAYER MODELING USING COUPLED PLASMA AND NEUTRAL TRANSPORT CODES

BY

D.P. STOTLER, D.P. COSTER, B.J. BRAAMS, ET AL.

May, 1992

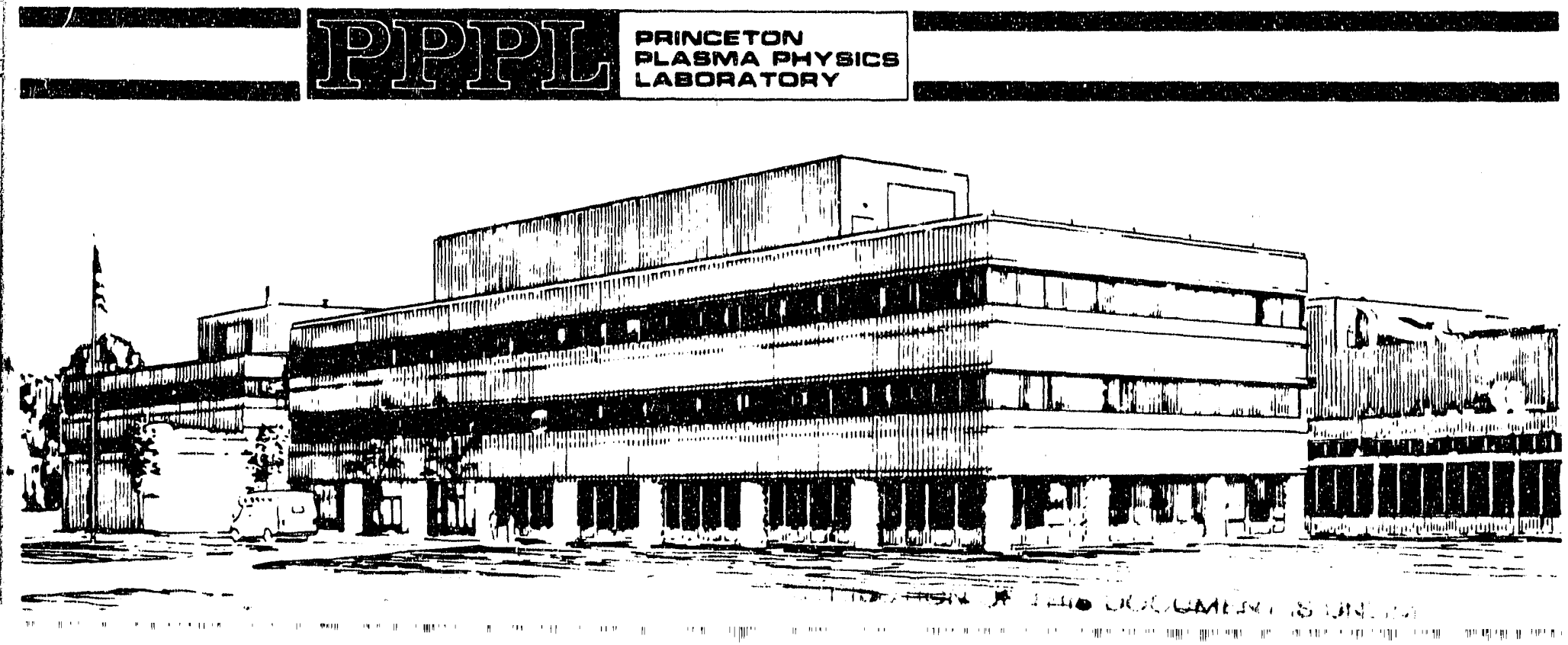




\section{NOTICE}

This report was prepared as an account of work sponsored by an agency of the United States Government. Neither the United States Government nor any agency thereof, nor any of their employees, makes any warranty, express or implied, or assumes any legal liability or responsibility for the accuracy, completeness, or usefulness of any information, apparatus, product, or process disclosed, or represents that its use would not infringe privately owned rights. Reference herein to any specific commercial produce, process, or service by trade name, trademark, manufacturer, or othenvise, does not necessarily constitute or imply its endorsement, recommendation, or favoring by the United States Government or any agency thereot. The views and opinions of authors expressed herein do not necessarily state or reflect those of the United States Government or any agency thereot.

\section{NOTICE}

This report has been reproduced directly from the best available copy.

Available to DOE and DOE contractors from the:

Office of Scientific and Technical Information P.O. Box 62

Oak Ridge, TN 37831;

Prices available from (615) 576-8401.

Available to the public from the:

National Technical Information Service

U.S. Department of Commerce

5285 Port Royal Road

Springfield, Virginia 22161

$703-487-4650$ 


\title{
Scrape-off Layer Modeling Using Coupled Plasma and Neutral Transport Codes
}

\author{
D. P. Stotler, D. P. Coster, B. J. Braams*, A. B. Ehrhardt, \\ C. F. F. Karney, and M. Petravic \\ Plasma Physics Laboratory, Princeton University \\ Princeton, NJ 08543
}

An effort is made to refine the neutral transport model used in the B2 edge plasma code by coupling it to the DEGAS Monte Carlo code. Results are discussed for a simulation of a high recycling divertor. It appears that on the order of 100 iterations between the two codes are required to achieve a converged solution. However, the amount of computer time used in the DEGAS simulations is large, making complete runs impractical for design purposes. On the other hand, the differences in the resulting plasma parameters when compared to the B2 analytic neutrals model indicate that it would be worthwhile to explore techniques for speeding up the coupled system of codes.

*Courant Institue of Mathematical Sciences, New York University. 


\section{Introduction}

The $\mathrm{B} 2$ code [1] is a 2-dimensional multi-fluid plasma transport code. Equations for conlinuity, momentum balance, jon energy balance, and electron energy balance are solved. Normally, B2 uses an analytic description of the neutral particle behavior in performing a self-consistent simulation of a scrape-off layer plasma. However, the approximations made in it are inadequate for use in detailed design work, especially for high recycling divertors. In particular, the B2 model takes into account only electron impact ionization; charge exchange and molecular reactions are ignored. For this reason, we have coupled B2 to the more complete DEGAS Monte Carlo neutral transport code [2]. DEGAS considers collision processes such as ionization, charge exchange, and dissociation. Several models for wall reflections are included. It can also handle general 3-dimensional geometries, although we assume hore toroidal symmetry as in B2. Note that B2 has been coupled to the EIREiVE Monte Carlo neutral code $[3, .$. and that DEGAS has been linked with the PLANET edge plasma code [5]. In fact, the procedures discussed here should generally be applicable to codes other than B2 and DEGAS.

We have previously modeled representative TFTR supershot and ohmic discharges with the coupled codes [6]; only a simple linking scheme was utilized. We discuss here application of the coupled codes to a divertor typical of proposed burning plasma experiments $[7,8]$. A more involved coupling scheme is required in this case. Even after 31 iterations, some secular variation in plasma parameters persists. At this point, the peak electron temperature and density near the plate have already dropped by $>40 \%$ from their initial B2-only values, and the plasma profiles along the plate have changed qualitatively. The amount of computer time required for the DEGAS calculations prevents the iterations from being carried further; a complete run of the coupled codes is too long to be practical. However, because of the significant differences in the results relative to those obtained with the B2 analytic neutral transport model, it is worth expending some effort to speed up the coupled system. 


\section{Basic coupling procedure}

A minimal procedure for coupling B2 and DEGAS consists of the following steps.

1. Run B2 to convergence using its analytic neutrals model.

2. Create DEGAS namelist input using a file produced by B2.

3. Run DEGAS; at the end, have it generate a file containing particle and energy source rates.

4. Have B2 read this file and restart with the plasma obtained at the end of the previous run;

5. At each time step during the B2 run, renormalize input source rates by the total current to the plate.

6. Repeat steps (2) through (5) until plasma variations are negligible.

In step (2), B2 provides DEGAS with information about the plasma grid, density, temperature, flow velocity, and the particle flux to the target plate.

We have modeled representative TFTR supershot and ohmic discharges with this simple coupling scheme [6]. For these cases, $4-5$ iterations were required between the two codes in order to reach a converged solution. In both runs, the final peak particle flux to the limiter was $\geq 40 \%$ higher than that found with the B2 analytic neutrals model alone. The magnitude of these differences indicates the need for a detailed neutral transport model such as the one provided by DEGAS if quantitative analyses of experimental data are to be carried out. Other examples are provided in Ref. [9].

\section{Simulations of a high recycling divertor}

One of the principal uses of the coupled B2-DEGAS code will be to aid in the design of divertors for future devices such as ITER [10] and BPX [8] (formerly known as CIT [7]). In this section, we describe extensions to the 
basic procedure which are required to simulate the high recycling regimes expected for these devices.

In a high recycling divertor, the interaction between the divertor plasma and the neutral gas is highly nonlinear, and the simple procedure outlined in section 2 fails to work. For instance, it is possible for the source rate returned by DEGAS to be so large as to immediately radiate all of the power flowing into the SOL. A slower approach to the desired self-consistent solution is required.

First, we begin the run with a recycling coefficient $\mathcal{R}$ which is well below unity, say, $\mathcal{R}=0.9$. As iterations between the two codes progress, $\mathcal{R}$ can be raised slowly to the desired value (e.g., $\mathcal{R} \simeq 1$ ). For the purposes of this investigation, however, we hold it fixed at 0.9 .

Secondly, we reduce gradually the contribution of the analytic B2 neutrals model to the solution and smooth out the contributions provided by subsequent DEGAS simulations. The algorithm we use for doing this can be written as

$$
S_{n}(t)=I_{\text {plate }, n}(t)\left\{f\left[\frac{S_{D, n}}{I_{D, n}}\right]+(1-f)\left[\frac{S_{n-1}}{I_{\text {plate }, n-1}}\right]\right\} .
$$

In this equation, $S_{n}$ represents the 2-dimensional ion source rate in B2 at the $n$-th iteration between the two codes; $I_{p l a t e, n}$ is the total current to the target plate. The normalized source rate $S_{n-1} / I_{\text {plate }, n-1}$ from the previous run is read in along with the source information provided by DEGAS $S_{D, n}$; $I_{D, n}$ represents the total current to the target plate used in the DEGAS calculation. The two contributions are combined with an arbitrary factor $f$ to form $S_{n}$. The array $S_{n} / I_{\text {plate }, n}$ is then written out by B2 for use in the next run. Here, we take $f=0.5$. The $t$ argument of $S_{n}$ and $I_{\text {plate }, n}$ indicates that the source rate is continuously renormalized to match the total current as B2 iterates. The source term appearing in the continuity equation is $\mathcal{R} S_{n}(t)$ (there is no net absorption in the DEGAS calculation).

To achieve optimum convergence, the differences between successive values of $S_{D, n}$ should be due only to the changes in the plasma provided by the B2 run between them. In practice, there is some amount of Monte Carlo noise inherent in $S_{D, n}$. By increasing the number of flights and by spliiting flights [2], the variance in the regions of greatest interest can be reduced to 
an acceptable level. Unfortunately, at least for the present problem, this increases substantially the computer time relative to that required for the calculations of section 2 .

When modeling an up-down symmetric double-null divertor, the $\mathrm{B} 2$ code is typically applied to just the outer, lower quadrant of the scrape-off layer (from midplane to the target plate); empirically, the outer half receives the greater heat flow [8]. In order to use the rectangular reference mesh of DEGAS most efficiently [2], it is a good idea to pare down the B2 grid io include only the region near the target plate.

Since B2 is usually restricted to a curvilinear, orthogonal mesh with flux surfaces as one coordinate, it is in general not possible to utilize the exact shape of divertors and limiters. DEGAS has no such limitations, so we have developed a mechanism for augmenting the grid to allow it to meet the material boundaries (the zones corresponding to those used by $\mathrm{B} 2$ are unaltered). In this way, the boundary conditions used by DEGAS can be chosen in a more realistic fashion. The densities and temperatures within these additional zones are assumed to fall exponentially (with specified scale lengths) from the values at the nearest edge of the $\mathrm{B} 2$ grid down to a predetermined minimum.

The example we consider is a $2.1 \mathrm{~m}$ version of CIT [7]; the plasma mesh used in DEGAS is shown in fig. 1. The B2 grid from which it is derived is an analytic approximation to a numerical equilibrium [7] with major and minor radii of $R=2.1 \mathrm{~m}$ and $a=0.65 \mathrm{~m}$, respectively, an elongation of 2 , a toroidal field on axis $B_{T}=10 \mathrm{~T}$, and a plasma current $I_{p}=11 \mathrm{MA}$. Only a few zones in the private flux region have been added; the remainder of the material boundary in the divertor region is enclosed within the $\mathrm{B} 2$ mesh.

The primary assumptions made in $\mathrm{B} 2$ for this simulation are: temperatures $T_{e}=T_{i}=500 \mathrm{eV}$ and densities $n_{e}=n_{i}=5 \times 10^{19} \mathrm{~m}^{-3}$ along the core plasma boundary; ion mass $=2.5 \mathrm{AMU}$ (equal mix of $\mathrm{D}$ and $\mathrm{T})$; thermal and particle diffusivities $\chi_{e}=3 \mathrm{~m}^{2} / \mathrm{s}, \chi_{i}=D=\chi_{t} / 3$ (no anomalous pinch term); and a plate recycling coefficient of $\mathcal{R}=0.9$. Parallel transport is classical; perpendicular transport is anomalous with the aforementioned diffusivities. The electron parallel heat flux is given by [1] $q_{\|}=q_{f} q_{S H} /\left(q_{f}+q_{S H}\right)$, where $q_{S H}$ is the Spitzer-Härm value and $q_{f}=c_{q} n_{e} T_{e} \sqrt{T_{e} / m_{e}}$ with $c_{q}=0.1$. The ion densities and fluxes are divided equally among deuterium and tritium 
when they are transferred to DEGAS.

Thirty-one iterations of the coupled codes have been made for this simulation. The evolution of the peak electron temperature at the plate sheath $T_{e, \max }$ and the total current to the plate $I_{\text {plate }}$ is shown in fig. 2. Global quantities such as $I_{\text {plate }}$ do not vary a great deal as the iterations progress. The peak temperatures and densities at the divertor plate sheath, however, fall by nearly $50 \%$. The peak heat flux (electron plus ion) to the target increases by $15 \%$.

The initial and final plasma profiles near the plate are disparate, as is exemplified by fig. 3. The density profiles of the initial and final run differ to an even greater extent; the location of the peak value on the plate sheath moves from well outside the separatrix to directly adjacent to the separatrix.

The reasons for the extent of these alterations are apparent when one considers the approximations made in the B2 neutral transport model. First, B2 treats unly electron impact ionization, while analysis of the data produced by DEGAS indicates that dissociation and charge exchange are also important in this problem. The poloidal and radial spreading of the ion source in B2 is performed as if the neutrals had a constant velocity [1]. In DEGAS on the other hand, a recycled neutral starts out with a velocity that is determined from a detailed wall reflection model; as the neutral propagates into the plasma, its velocity can be altered by a charge exchange event. Finally, in distributing the ion source rate along a flux surface, B2 limits the number of ions deposited in the zone directly in front of the plate sheath to be no more than $50 \%$ of the total for that flux surface. After 31 iterations between the two codes, however, we find that DEGAS predicts a source rate distribution which would clearly exceed this limit. In fact, the source rate density in many of the zones adjacent to the sheath is more than an order of magnitude greater than that found further away from the plate.

\section{Improvements to the coupled system}

These results indicate that a careful calculation of the SOL plasma behavior requires a detailed neutral transport model such as that provided by DEGAS. However, on the order of 100 iterations [3] may be needed to achieve convergence between the plasma and neutral transport codes; for example, 
fig. 2 indicates that noticeable variations in the plasma parameter values persist even after 31 iterations. Given that each of the present DEGAS simulations requires approximately an hour of computer time (on a Cray-2), a complete calculation would be too long to be of practical use.

We are consequently investigating methods of speeding up and improving the coupled B2-DEGAS system. The simplest approach would be to use the results of a coupled calculation to enhance the quality of the analytic neutrals model in B2. Namely, there are adjustable parameter's in the B2 model such as the poloidal and radial velocity of neutral atoms. By comparing the ion source rate computed by B2 against a DEGAS source based on the same plasma, it would be possible to calibrate the $\mathrm{B} 2$ model against the more detailed DEGAS result. Doing this would not only improve the quality of B2-only runs, but also provide a better first plasma for use in future coupled B2-DEGAS runs. Work along these lines is under way.

The success of the B2-EIRENE codes $[3,4]$ indicates that a reasonably fast coupled system can be developed. We discuss below the steps we could take to incorporate into B2-DEGAS some of the techniques developed for B2-EIRENE. These methods could be applied to other codes as well.

The plasma-neutral transport system could be enhanced either by speeding up DEGAS or by increasing the efficiency of the coupling (note that the run time required by $\mathrm{B} 2$ is not significant). For example, it makes sense to have the plasma code call for a recalculation of the ion source rate whenever the plasma conditions have changed substantially (i.e., begin calling DEGAS well before $\mathrm{B} 2$ converges) $[3,4]$; this would alleviate problems with high energy loss rates for $\mathcal{R} \simeq 1$.

If the neutral density profile were passed to $B 2$ instead of the ion source rate and if $\mathrm{B} 2$ had access to the atomic reaction rate data, the ion source rate could be updated continuously as the plasma temperature and density evolved $[3,4]$. In practice, however, a more approximate procedure would have to be used since B2 cannot treat adequately certain reactions such as charge exchange.

The number of flights used in DEGAS could be reduced if correlated sampling were employed $[11,12]$. This is a method for determining the differential change of source rate with respect to variations in the baciground plasma. The simplest implementation of this procedure wonld involve recording the 
initial random number seed of each Monte Carlo flight in the first DEGAS run and starting each flight in subsequent runs with the same seed it had in the initial run [11]. This technique would largely eliminate run-to-run variations due to Monte Carlo noise without requiring a large number of flights.

Some savings in run time could be obtained by paring down the number of profiles kept by DEGAS to the handful that are required by the plasma code [11]. The full set could be re-enabled during the final run in order to obtained detailed results for subsequent analysis.

Since a substantial fraction of the time used in the DEGAS calculations is spent generating pseudo-random numbers, it would also be worthwhile to improve the speed of the random number generator, Efforts along these lines are under way.

\section{Conclusions}

Detailed analyses of experimental data and predictions of future devices require greater accuracy than is provided by the analytic neutral transport model in the B2 edge plasma code. To improve the treatment of neutral transport in B2, we have linked it to the Monte Carlo neutral transport code DEGAS and presented here initial results of the coupled system for limiter and divertor geometries. Unfortunately, it appears that, in the case of high recycling divertors at least, the amount of computer time required to complete a run is too large to make this a practical technique. On the other hand, the differences in the results relative to those obtained with the B2 neutrals model are sufficiently large to make it worthwhile to search for ways to speed up the coupled plasma-neutral transport system. The most promising possibility is the use of correlated sampling. With it, the number of flights used in DEGAS could be ciecreased without impeding the ability of the plasma code to react to changes in the neutral density and vice-versa.

\section{Acknowledgments}

The authors wish to thank D. Reiter for providing nany useful suggestions on improving the coupled B2-DEGAS codes. This work was supported by 
U.S. DOE Contract No. DE-AC02-76-CHO-3073. 


\section{References}

[1] B. J. Braams, Computational Studies in Tokamak Equilibrium and Transport, Thesis, University of Utrecht, 1986.

[2] D. Heifetz, D. Post, M. Petravic, J. Weisheit, and G. Bateman, J. Comp. Phys. 46 (1982) 309.

[3] M. F. A. Harrison, E. S. Hotston, and G. P. Maddison, Commission of the European Communities, NET Report Nr. 100, EUR-FU/80/91-100 (1991).

[4] G. P. Maddison et al., in: Proc. 18th European Conf. on Controlled Fusion and Plasma Physics, 1991, Berlin, Part III, p. 197.

[5] M. Petravic and G. Kuo-Petravic, Nucl. Fusion $\underline{30}$ (1990) 1148.

[6] D. P. Stotler et al., in: 1990 IEEE Int. Conf, on Plasma Science, Oakland, p. 88.

17] R. Parker et al., in: Proc. 12th Int. Conf. on Plasma Physics and Controlled Nuclear Fusion Research, 1988, Nice, Vol. 3, p. 341.

[8] R. J. Goliston et al., Princeton Plasma Physics Lab, Burning Plasma Experiment Report X-910311..PPL-22 (1992); to appear in Fusion Technol. (1992).

[9] R. Budny, M. G. Bell, D. Coster, D. K. Owens, and D. Stotler, in: these Proceedings (PSI-10).

[10] ITER Conceptual Design Activity Final Report, ITER Documentation Series No. 16 (International Atomic Energy Agency, Vienna, 1991).

[11] D. Reiter, IPP KFA Jülich, Private Communication (1991).

[12] J. Spanier and E. M. Gelbard, Monte Carlo Principles and Neutral Transport Problems (Addison-Wesley Publishing Company, Reading, Massachusetts, 1969). 


\section{Figures}

Fig. 1. Geometry of $2.1 \mathrm{~m}$ CIT [7] used in DEGAS calculations. The divertor plate is represented by the bottom edge of the mesh; the X-point is on the left edge near the middle of the grid.

Fig. 2. Values of (a) the maximum $T_{e}$ on the plate sheath and (b) the total on current to the plate $I_{\text {plate }}$ at the end of each B2 run for 31 iterations of the coupled B2 and DEGAS codes.

Fig. 3. Initial (solid line; B2 inalytic neutrals model) and final (dashed; after 31 iterations of the coupled codes) $T_{e}$ as a function of distance along the plate sheath relative to the separatrix. 


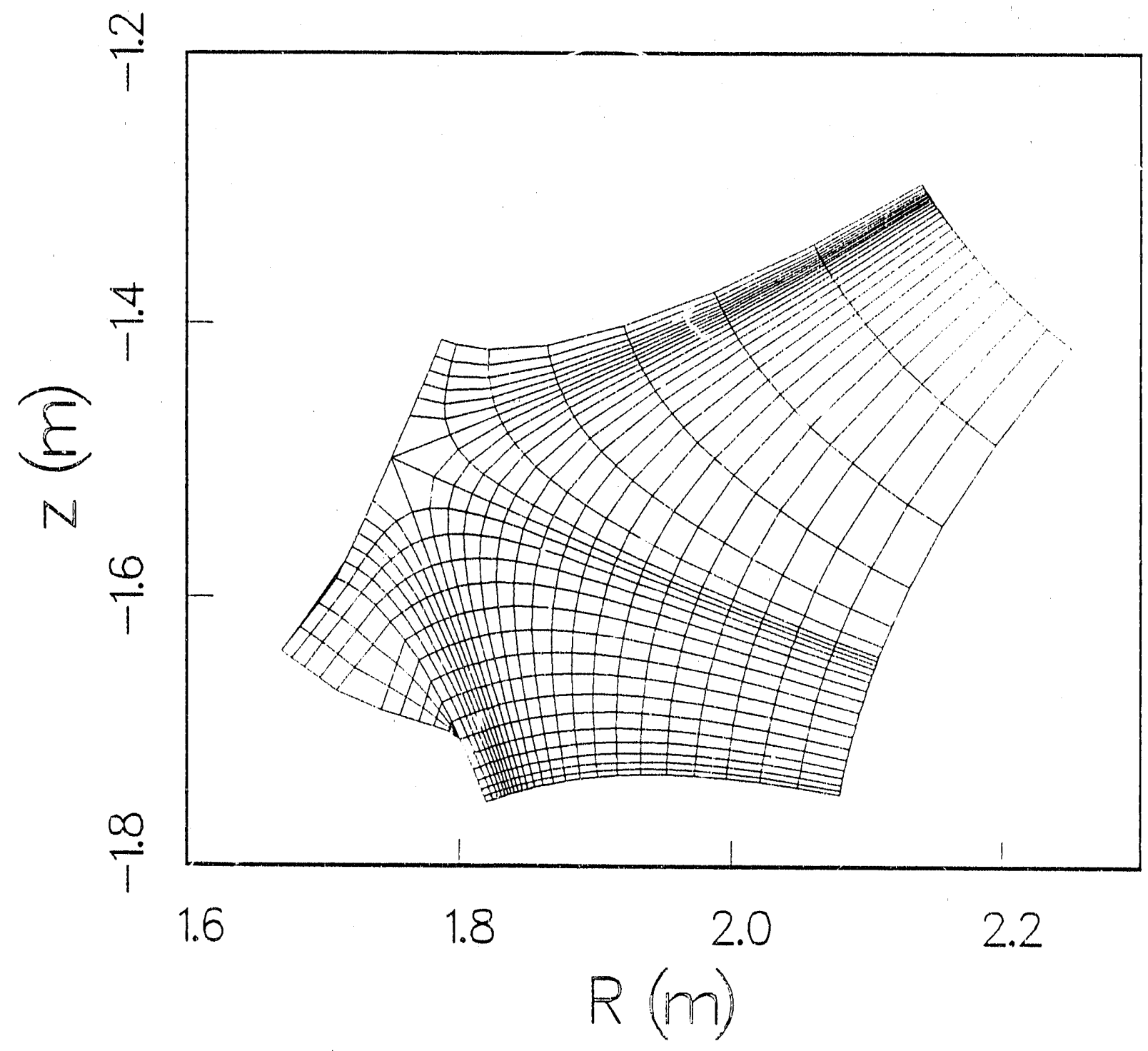

Fig. 1 

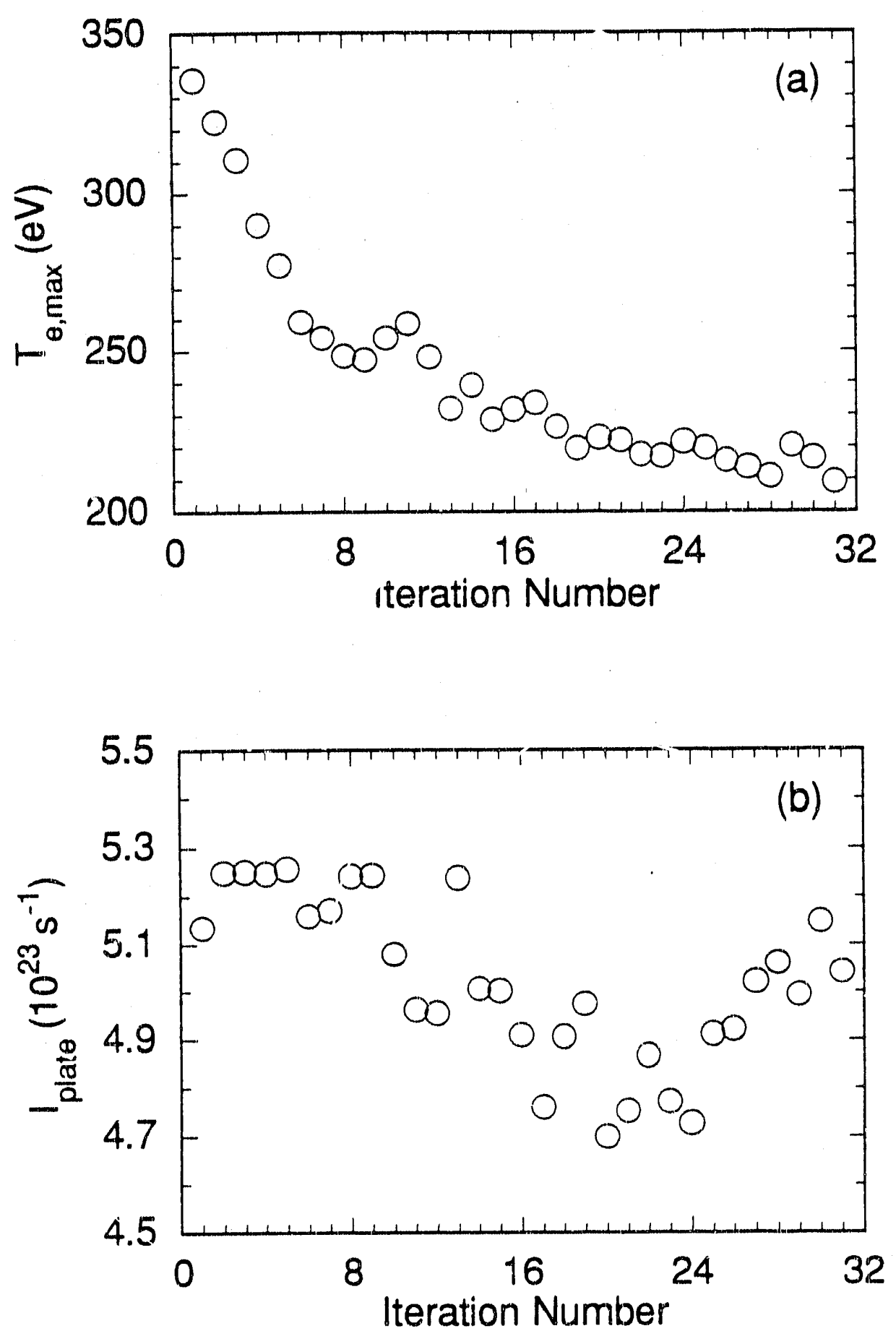

Fig. 2 


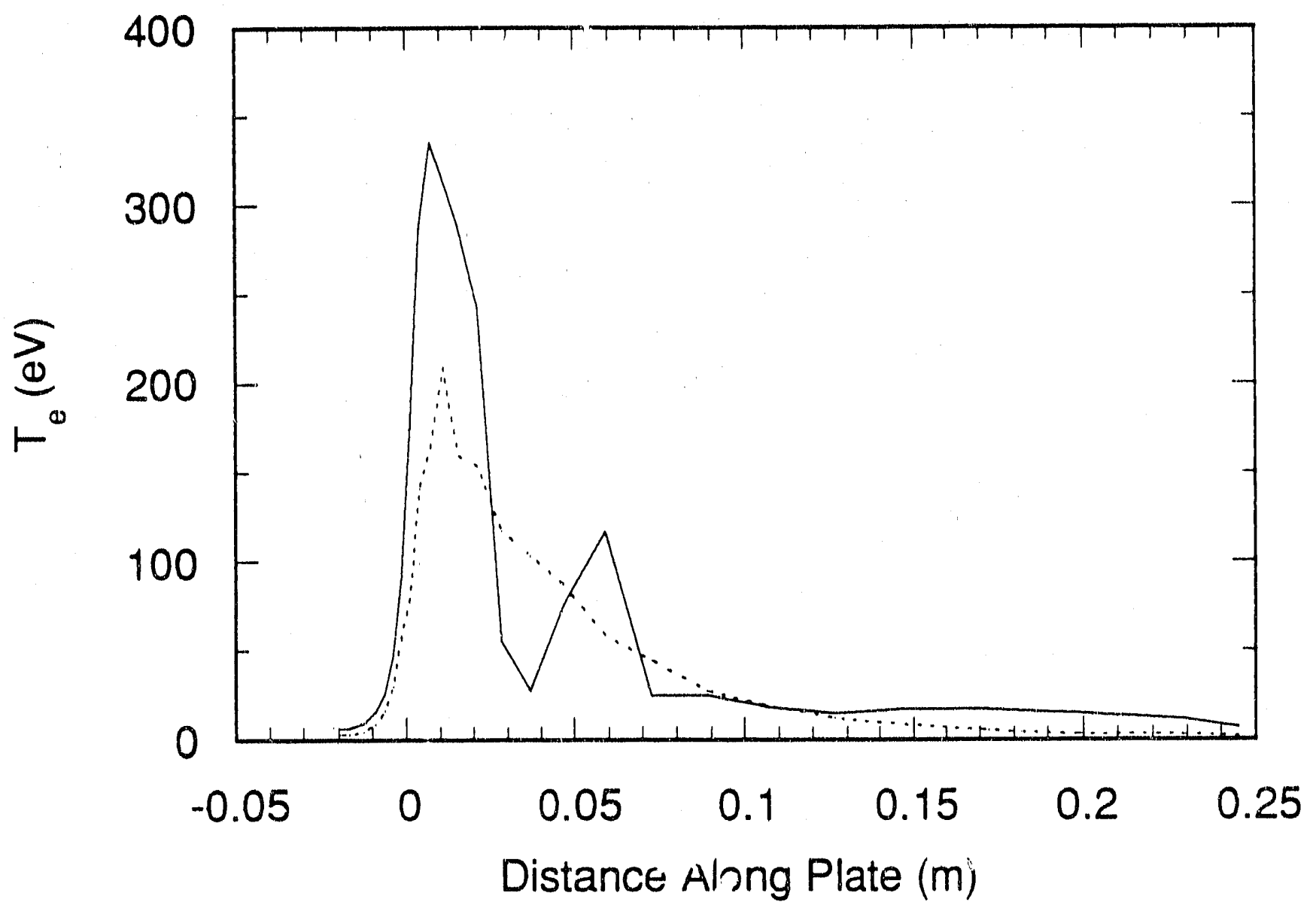

Fig. 3 
Dr. F. Peoloni, Univ, of Wollongong, AUSTRALIA

Prot. M.H. Brennan, Univ. of Sydnoy, AUSTRALIA

Plasma Posearch Leb., Australian Nat. Univ., AUSTRALIA

Prof. I.P. Jones, Findors Univ, AUstraLia

Prof. F. Cap, Inst for Theoretical Physics, AUSTRIA

Prot. M. Hoindler, Institut for Theoredectio Physik, AUSTAIA

Prot. M. Goossens, Astronomisch Instibut, BELGIUM

Ecolo Royde Nilitire, Leb. do Phy. Plesmas, BELGIUM

Conmission-Eurapeen, DG. XII-FUston Prog., BELGIUM

Prot. R. Boudaus, Rijkeuniveraibst Gent, BELGIUM

D. P.H. Sakanaka, Instituto Fialon, BPAZIL

Inettuso Nediond De Ponquieas Espaciaie-INPE, BRUZIL.

Documents Oritice, Alomic Energy of Ceneda Lid., CANADA

Dr. M.P. Bectynakd, MPB Tectnotogies, Inc., CANADA

Dr. H.M. Skaregard, Univ. of Seckaktowen, CANADA

Prof. J. Tolchmann, Univ. of Montreal, CANADA

Prot. S.R. Sreenivasen, Univ. of Galgary, CANADA

Prot. T.W. Johnston, INAS-Energio, CANADA

Dr. R. Botton, Contro canadion de iusion magndioquo, CANADA

Dr. C.R. James "Univ. of Aberta. CANAOA

Dr. P. Luktic, Komonak tho Univorsita, CZECHOSLOVAKIA

The Librarian, Culthem Laboratory, ENGLAND

Librery, R61, Ruthertord Appletion Laboratory, ENGLAND

Mrs. S.A. Hulctinsoon, JET Librery, ENGLAND

Dr. S.C. Shema, Univ. of South Pacific, FIJI ISLANDS

P. Muthonen, Univ, of Heisinki, FINLAND

Prot. M.N. Buseac, Ecote Polywechnique,. FRANCE

C. Moutrot, Lab. de Physique des Milisux Ioniser, FRANCE

J. Rodot, CENCADARACHE - Bat 506, FRANCE

Prot. E. Economow, Univ, of Crote, GAEECE

M6. C. Rinn, Univ, of loannina, GPEECE

Dr. T. Mud, Acadomy Bibliographic Ser., HONG KONG

Preprint Library, Hungarian Acadomy of Sci., HUNGAAY

Dr. B. DasGupta, Saha Inst. of ivictser Physics, INDIA

Dr. P. Kaw, Inst. for Plasma Research, INDIA

Dr. P. Rosenew, lerael inet. of Tectinology, ISAAEL

Lubrerian, Intommitional Conter for Theo Physics, ITALY

Miss C. De Palo, Associazione EURATOM-ENEA, ITALY

Dr. G. Grosso, lotituto di Fieica ded Plasma, ITALY

Prof. G. Rostangni, lsttuto Gas lonizzati Dol Cnr, ITALY

Dr. H. Yamato, Toshiba Ros a Dovol center, JAPAN
Prof. I. Kewakemi, Hiroshima Univ., JAPAN

Prot. K. Nishikawa, Hiroshima Univ., JAPAN

Drector, Jepan Atomic Energy Research Inst., JAPAN

Prot. S. Itoh, Kyushu Univ., JAPAN

Research Into, Cr., National Instit. for Fusion Scienca, JAPAN

Prof. S. Tanaka, Kyolo Univ., JAPAN

Librery, Kyoto Univ., JAPAN

Prot. N. Inous, Univ, of Tokyo, JAPAN

Secretary, Plauma Section, Electrotactinical Lab., JAPAN

5. Mori, Tectmiced Advizor, MAERI, JAPAN

Dr, O. Mured, Kumamoto Inst. of Tectrology, JAPAN

J. Hyeon-Sook, Korea Alomic Enorgy Reseanch Inst, KOREA

D.I. Choi, The Korea Adv. Inat, of Sd. \& Toch., KOREA

Prot. B.S. Llay, Univ. of Waikato, NEW ZEALAND

Inat of Physias, Chines Acad SCA PEOPLE'S REP. OF CHINA

Librery, Inet. of Plasma Physics, PEOPLE'S REP. OF CHINA

Tringhu Univ. Lbrary, PEOPLE'S REPUBLIC OF CHINA

Z. L, S.W. Inat Physics, PEOPLE'S REPUBLIC OF CHINA

Prof. J.A.C. Comral, Instituto Superior Tecnico, PORTUGAL.

Dr. O. Potrus, AL I CUzA Univ., ROMANIA

Dr. J. Villers, Fucion Studies, AEC, S. AFAICA

Prof. M.A. Hellberg, Univ, of Natal, S. AFFICA

Prot. D.E. Kim, Pohang Inst. of Sol, Tech., SO. KOAEA

Prot. C.I.E.M.A.T, Fusion Division Library, SPAIN

Dr. L. Stonflo, Univ. of UMEA, SWEDEN

Library, Poyd inst. of Tratinology, SWEDEN

Prot. H. Withotmeon, Chaimers Univ. of Tech., SWEDEN

Centro Phys. Des Plasmac, Ecole Polytech, SWITZERLAND

Bibliothes, Inst. Voor Plasma-Fysica, THE NETHERLANDS

Aset. Prot. Dr. S. Cakir, Midde East Tech. Univ., TURKEY

Dr. V.A. Gulthikh,Sa. Res, Inst. Eloctrophys. I Apparatus, USSR

Dr. D.D. Arubov, Siberian Brench of Acaderny of Saj., USSA

Dr. G.A. Elieceov, I.V. Kunchatov Inst, USSA

Librorian, The Ukr,SSA Academy of Sciencer, USSA

Dr. L.M. Kovrizhnykh, Inst. of Generay Physics, USSR

Komtoractungsantage GmbH, Zentralbibliothek, W. GERMAlir

Biblothak, Inst. For Plasmatorschung, W. GERMANY

Prof. K. Schinder, Ruhr-Uniwer sitat Bochum, W. GERMANY

Dr. F. Wagner, (ASDEX), Max-Planck-Institut, W. GERMANY

Librarian, Max-Planck-Institut, W. GERMANY

Prof. R.K. Janew, Inst. of Ptysics, YUGOSLAVIA 

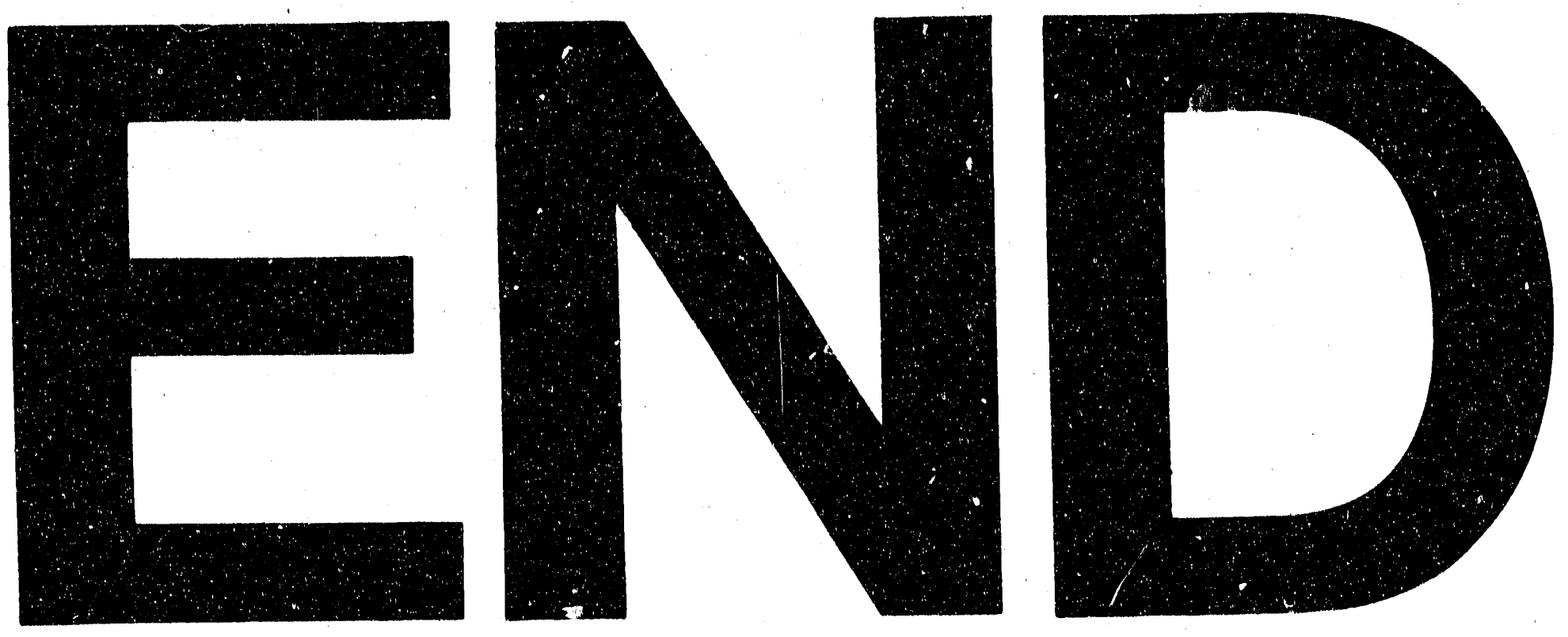

I
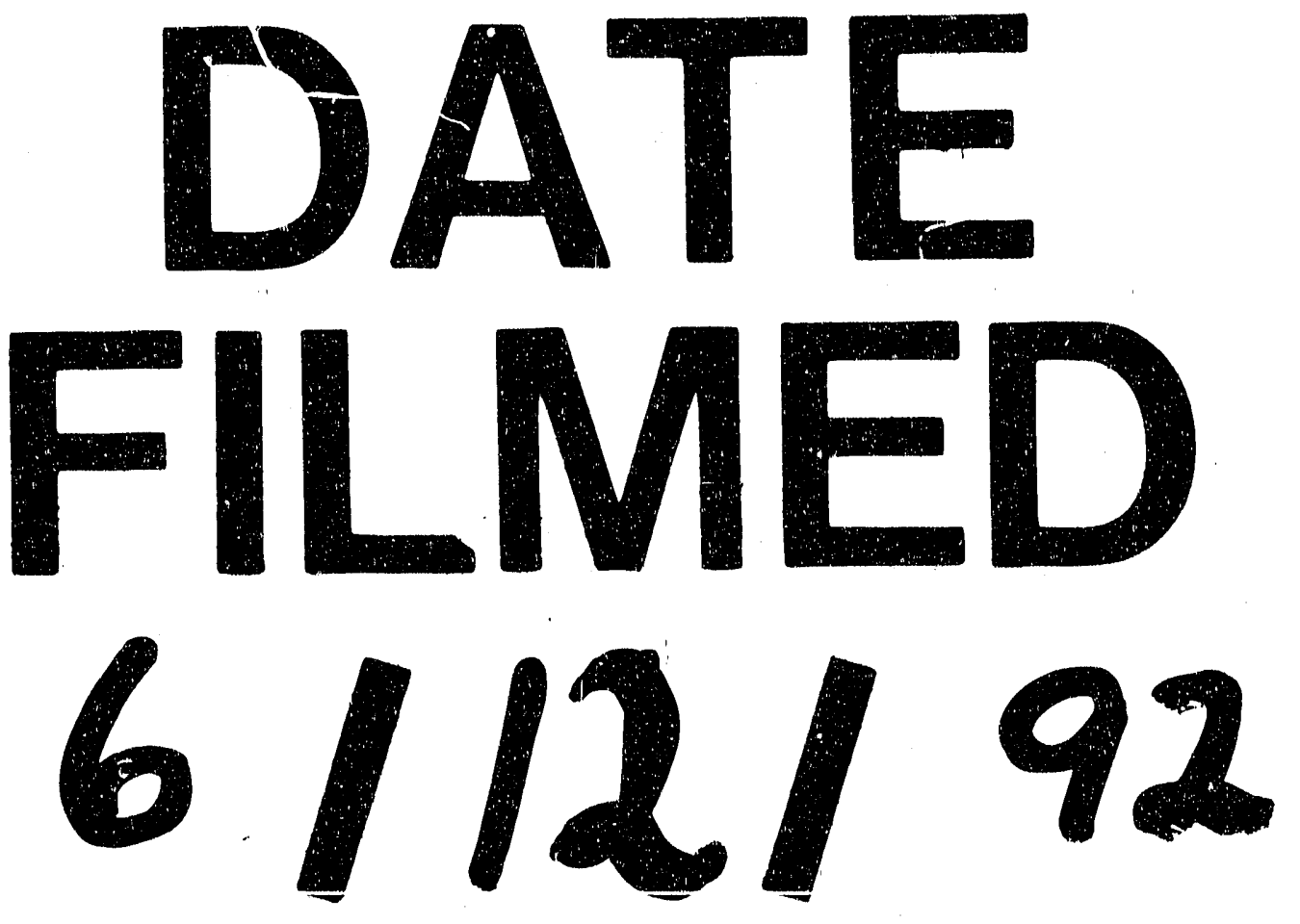
